understood why the $20 \mathrm{G} i \mathrm{v}$ was functioning "great." If we had used the $20 \mathrm{G}$ for the dopamine and other drugs, serious problems could have arisen. We cannot ascertain how this happened as all concerned deny any involvement. However, somebody must have cut the iv line and made a knot in the tubing without telling us. The remote possibility that this happened by accident must also be considered.

We bring this case to your readership's attention for two reasons: first, a "hidden iv" should preferably not be used unless absolutely necessary and, second, a "hidden" $i v$ working "great" may not be as good as you think.

Andrew Kim MD

John G. Brock-Utne MD PhD

Stanford, California

\section{Misconception of tracheal intubation using a fibreoptic bronchoscope}

To the Editor:

The role of the fibreoptic bronchoscope in the management of patients with a history of difficult intubation is well established. However, it has been suggested that this is an intubating technique with direct vision. ${ }^{1,2}$ This is incorrect. Tracheal intubation under direct vision refers to the placement of an endotracheal tube (ETT) under direct laryngoscopy. Fibreoptic intubation involves advancing the tip of the bronchoscope under "fibreoptic" vision into the glottic opening until the tip approaches the carina. The ETT is then advanced slowly and "blindly" over the bronchoscope into the trachea. The bronchoscope merely functions as an intubating guide, like a "gum elastic bougie," during this manoeuvre. At no time during the insertion of the ETT over the bronchoscope can the tip of the ETT be directly visualized. As a result, tracheal intubation using a fibreoptic bronchoscope should be used with great caution in patients with retropharyngeal abscess, pedunculated polyps or tumours at the vocal cords, and foreign body in the upper airway.

Although tracheal intubation using the fibreoptic bronchoscope is a safe and effective intubating technique for many patients, its limitations cannot be overlooked.

\section{Orlando R. Hung MD FRCPC}

Department of Anaesthesia, Dalhousie University, Queen Elizabeth II Health Sciences Centre, Halifax, Nova Scotia, Canada B3H 2 Y9

\section{REFERENCES}

1 Cobley $M$, Vaughan RS. Recognition and management of difficult airway problems. Br J Anaesth 1992; 68: 90-7.

2 Roberts JT. Fiberoptic intubation and alternative techniques for managing the difficult airway. American Sociery of Anesthesiologists 1997 Annual Meeting Refresher Course Lecture \#243, 1-4.

\section{Physostigmine, propofol and the $G A B A_{A}$ receptor}

To the Editor:

Fassoulaki et al., are to be congratulated for their observation that physostigmine increases the dose of propofol required to induce anaesthesia. ${ }^{1}$ However, their comments regarding the effects of propofol on the $\mathrm{GABA}_{\mathrm{A}}$ receptor require further clarification.

Biochemical, electrophysiological and molecular studies indicate that propofol increases $\mathrm{GABA}_{\mathrm{A}}$ receptor activity by binding to a site that is distinct from the benzodiazepine recognition site. ${ }^{2}$ Propofol increases receptor function by at least three mechanisms. However, it is not certain which of these mechanisms account for propofol's clinical effects. ${ }^{3}$ Furthermore, the in vitro effects of propofol on the $\mathrm{GABA}_{\mathrm{A}}$ receptor are highly dependent on experimental procedure (e.g., the concentration of GABA) or biological factors (e.g., strain of mice). Therefore, reports that correlate the behavioural properties and in vitro actions of anaesthetics must be interpreted with caution. ${ }^{4}$ Nevertheless, increasing evidence suggests that the $\mathrm{GABA}_{\mathrm{A}}$ receptor is a primary site for propofol's neurodepressive effects. The observation that physostigmine (a drug which increases general arousal) alters the potency of propofol does not detract from this suggestion. Physostigmine also antagonizes the sedative properties of midazolam and a clear relationship has been cstablished between midazolam's sedative-hypnotic effects and the flumazenil-sensitive site on the GABA $_{A}$ receptor. ${ }^{2,5}$ The report by Fassoulaki $e t a l$. serves to remind us that clinically relevant concentrations of anaesthetics influence multiple types of receptors (to a greater or lesser degree). These receptors act in concert to "fine tune" consciousness or create the complex behavioural state we refer to as general anaesthesia.

\section{B. Orser MD PhD FRCPC \\ Toronto, Canada}

\section{REFERENCES}

1 Fassoulaki A, Sarantopoulos $C$, Derveniotis Ch. Physostigmine increases the dose of propofol required to induce anaesthesia. Can J Anaesth 1997; 44: 1148-51. 